\title{
La politique de Dieu: una traducción desconocida de la obra de Quevedo, en un manuscrito del siglo XVII ${ }^{1}$
}

\author{
María José ALONSO VELOSO \\ Universidad de Santiago de Compostela \\ mariajose.alonso@usc.es
}

\section{RESUMEN}

Este artículo pretende dar noticia del hallazgo de una desconocida traducción al francés de la obra Política de Dios, de Francisco de Quevedo, en un manuscrito del siglo XVII custodiado en una biblioteca de Francia. La localización del códice otorga credibilidad a las noticias del controvertido librero Roberto Duport, quien mencionaba ya versiones francesas e italianas previas a su edición zaragozana de 1626. Al tiempo, obliga a corregir las afirmaciones de la crítica, que suponía que en Francia sólo había interesado la obra burlesca de Quevedo hasta épocas recientes, particularmente el Buscón y los Sueños, y negaba la existencia de traducciones al francés de su literatura política debido a la falta de testimonios manuscritos o impresos. De hecho, hay cada vez más indicios del interés que en Europa suscitaron sus textos políticos y morales de forma inmediata, en los siglos XVII y XVIII. La traducción, titulada La politique de Dieu, le gouvernement de Jesus Christ et la tirannie de Satan, como las versiones primitivas que le sirvieron de modelo, destaca por su fidelidad a la fuente, sorprendente si se compara con casos como el del Buscón de La Geneste. De autor desconocido, esta versión francesa se dedica a un consejero de la corte de Luis XIII, presumiblemente Gabriel Maillot, «Conseiller du Roy controlleur ordinaire des Guerres», a

\footnotetext{
${ }^{1}$ Este trabajo se inscribe en una línea de investigación sobre la recepción europea de la obra de Quevedo, con financiación nacional del programa «Ramón y Cajal», del Ministerio de Economía y Competitividad (referencia RYC-2012-10138), y autonómica a través del proyecto «La transmisión de la obra de Quevedo en el contexto intelectual europeo: traducción y recepción», de la Consellería de Cultura, Educación y Ordenación Universitaria de la Xunta de Galicia (referencia EM2014/007).
} 
quien el traductor transmite un llamativo agradecimiento de Quevedo, que debía de estar vivo entonces, un hecho que avalaría la datación temprana de la traducción.

Palabras clave: Quevedo, Política de Dios, Politique de Dieu, traducción francesa desconocida, manuscrito del siglo XVII.

\begin{abstract}
This article aims to give news about the discovery of an unknown translation into French of Francisco de Quevedo's Politica de Dios, in a manuscript dated in the 17th century and preserved in a library located in France. The finding of this codex confirms the credibility of the information given by the controversial bookseller Roberto Duport, who already mentioned some French and Italian versions prior to his edition, printed in Zaragoza in 1626 This translation also corrects the claims of the critics, who have assumed that French readers were interested only on Quevedo's burlesque works, particularly the Buscón and the Sueños, until recent times. The existence of translations into French of his political literature has been also denied due to the lack of handwritten or printed evidences. In fact, there are growing signs about the interest that their political and moral texts raised in Europe immediately, in the 17th and 18th centuries. This translation, entitled La politique de Dieu, le gouvernement de Jesus Christ et the tirannie of Satan, as the "primitive versions» that were used as its model, stands out for its fidelity to the source, a surprising fact if compared with examples as the Buscón translated by La Geneste. Written by an unknown author, this French version is dedicated to a counselor of the Court of Luis XIII, presumably Gabriel Maillot, "Conseiller du Roy controlleur ordinaire des Guerres», whom the translator conveys a striking appreciation from Quevedo, who should be alive even then. This fact should support an early dating for the translation
\end{abstract}

Key words: Quevedo, Política de Dios, Politique de Dieu, unknown French translation, manuscript of the 17 th century.

«Por haberme pedido muchas veces de Francia e Italia, y de diferentes partes de España, con instancia, cualesquier obras de don Francisco de Quevedo Villegas, y habiendo entendido esta Política de Dios andaba manuscripta con grande estimación y sabiendo que en la lengua francesa y la italiana estaba traducida, hice diligencia hasta que tuve una copia» ${ }^{2}$. Estas palabras de Roberto Duport forman

\footnotetext{
${ }^{2}$ Sobre el éxito de la obra, véase P. Jauralde (1999, pp. 400-409), quien afirma que «el manuscrito debió de correr de mano en mano» (p. 400), que «Quevedo muestra su originalidad convirtiendo en libro de éxito un tratado político sobre el buen gobierno» ( $\mathrm{p}$. 401) o que «es la primera vez que el escritor recibe un reconocimiento público y generalizado -el éxito editorial- por una obra seria» (p. 405). C. Peraita (1997, p. 68, nota 2), citando datos de J. O. Crosby, estima que «la comunidad real de lectores de la Política debió ser $[\ldots]$ muy amplia [...] hubo nueve ediciones en 1626, con un número total de 12.000 ejemplares. Se reedita en 1648, 1650 y $1655 »$.
} 
parte de los preliminares de la edición del tratado político quevediano publicada en Zaragoza en 1626, sin la autorización de su autor, y se encuentran también en otros testimonios de las llamadas «versiones primitivas» ${ }^{3}$, por ejemplo el manuscrito Frías. Duport fue un conocido librero con el que Quevedo mantuvo una estrecha relación editorial y que estuvo implicado en numerosas ediciones de sus obras, concentradas en la tercera década del siglo XVII, en circunstancias y con una posible intervención del autor aún no del todo claras ${ }^{4}$. Su afirmación de que, ya en la tercera década de la centuria y en el mismo momento de su llegada a la imprenta, la obra había sido traducida al francés y al italiano ha sembrado la duda y el desconcierto entre los críticos: no existe constancia documental alguna de tales versiones a las citadas lenguas romances en el siglo XVII, y sólo se conocen dos impresiones con una traducción italiana publicadas a comienzos del XVIII (Mantua, 1701 y Venecia, $1709)^{5}$. Existen también una temprana edición polaca (Varsovia, 1645) y dos inglesas tardías (Londres, 1715 y 1720), ${ }^{6}$ pero Francia parecía haber permanecido impermeable al pensamiento político quevediano hasta épocas más recientes ${ }^{7}$.

La falta de testimonios de una posible difusión inmediata en otras lenguas obligaba a concluir que la afirmación de Duport no se basaba en hechos reales ${ }^{8}$ :

${ }^{3}$ A partir de este punto, cuando use tal designación, me estaré refiriendo a dos manuscritos («Heredia Spínola» y «Frías») y a las ediciones de Zaragoza publicadas en 1626, pero también a otras sucesivas y derivadas directamente de alguna de ellas: dos de Barcelona, una de Pamplona y una de Milán, todas ellas publicadas también en 1626. Sigo los criterios de las ediciones de J. O. Crosby (1966) y E. Díaz (2012).

${ }^{4}$ Duport promovió hasta ocho ediciones de sus obras en el lustro comprendido entre 1626 y 1630, a las que hay que sumar las ya póstumas de La fortuna con seso y la hora de todos (1650) y Virtud militante (1651). Se trata de Política de Dios (1626), el Buscón (1626), Desvelos soñolientos (1627), El peor escondrijo de la muerte (1629), Memorial por el Patronato de Santiago (1629), Cuento de cuentos (1629), Doctrina moral (1630) y El chitón de las tarabillas (1630). En todos los casos el editor es Roberto Duport, y la impresión se realiza en Zaragoza, por Pedro Vergés, salvo El peor escondrijo, impresa por Juan de Larumbe. Tomo estos datos de A. Rey (1994-1995, pp. 168-169), quien ofrece más información a propósito de las confusas relaciones entre Quevedo y Duport. Sobre las obras póstumas, pueden consultarse las ediciones de L. Schwartz (2003) y A. Rey (1985).

${ }_{5}^{5}$ Una tercera, publicada en Trento, por Antonio Brunati, carece de fecha; según J. O. Crosby (1966, p. 593), es similar a la edición de Venecia en 1709.

${ }^{6}$ Sobre la traducción inglesa de la primera parte de Política de Dios, inserta en la polémica entre los whigs y los tories, y de la segunda, de acentuado antimaquiavelismo, véase Alonso Veloso (2016a y 2016b).

${ }^{7}$ Ofrecen información sobre algunas traducciones de Política de Dios A. Fernández-Guerra (1946, p. CX), L. Astrana (1943, p. 1439 y 1946, p. 773 ) y J. O. Crosby (1966, pp. 588593), entre otros. Sobre la difusión polaca de Política de Dios, remito a T. Eminowicz (1984) y E. Kwiatkowska Farys (2002).

${ }^{8}$ No obstante, debe tenerse en cuenta que ya en la «Aprobación» de la primera edición de Marco Bruto, en 1644, Diego de Córdoba enfatizaba los muchos textos de Quevedo 
sería hiperbólica y reflejaría tópicos preliminares habituales, con los que el editor habría pretendido encarecer el éxito y el interés que Política de Dios había despertado en el ámbito europeo incluso antes de la publicación de la princeps española en 1626. Una mera estrategia editorial del avispado librero para animar las ventas.

En referencia a la carta de Duport, «l'Avis au lecteur, qui précède la Política de Dios», E. Mérimée (1886, p. 442) advertía:

Je n'ai trouvé aucune trace de cette prétendue traduction française; si la déclaration du librarire Robert Duport n'est pas simplement une manière de recommander l'ouvrage qu'il éditait, elle ne peut faire allusion qu'à des traductions manuscrites.

Y un poco más adelante, después de enumerar las ediciones y traducciones conocidas de obras de Quevedo en Francia (Sueños, Discurso de todos los diablos, Buscón y Cartas del caballero de la Tenaza, así como recopilaciones de obras diversas), afirmaba:

Il n'existe point de traductions d'autres ouvrages de Quevedo, ni de ses poésies [...] les seuls ouvrages qui répandirent son nom en France furent ses oeuvres satiriques et humoristiques en prose (p. 455).

Se trata de una opinión generalizada, que se ha mantenido, como las propias dudas, hasta la actualidad. En un estudio mucho más reciente, M. Roig Miranda (2011, p. 238) señalaba que «hasta el siglo XIX, los franceses sólo tendrán traducciones de esas cuatro obras», aludiendo al Buscón, los Sueños, el Discurso de todos los diablos y Cartas del Caballero de la Tenaza. No obstante, apuntaba a propósito de las noticias de Duport sobre Política de Dios: «Además es posible también que hayan circulado traducciones manuscritas».

El propósito de este artículo es dar noticia del hallazgo de una desconocida traducción manuscrita al francés del tratado político de Quevedo, con el título $L a$ politique de Dieu, le gouvernement de Jesus Christ et la tirannie de Satan, en un manuscrito copiado en el siglo XVII y conservado en una biblioteca francesa. Se

«traducidos en los idiomas italiano, inglés, flamenco, francés y latino» (2012, p. 698). Y su primer biógrafo, Pablo de Tarsia, afirmaba en 1663, también a propósito del conjunto de sus obras, que «los libros impresos han sido recibidos con tanto aplauso de todas las naciones que algunos los han traducido en su lengua, para gozar de las agudezas y sentencias engeridas en cada palabra; y muchos se han divulgado en los idiomas latín, inglés, italiano y francés» $(1988$, p. 40). 
trata del primer testimonio que revela un interés temprano por la obra en Francia, y que obliga a revisar la afirmación de que no existieron en dicho país traducciones de sus textos «serios» hasta época reciente.

La localización de este códice manuscrito, permite, por una parte, confirmar la veracidad de las afirmaciones de Roberto Duport; y por la otra, arrojar nueva luz sobre el verdadero alcance de la difusión europea de Quevedo, especialmente en lo que atañe a sus tratados graves, políticos o morales, y particularmente en el ámbito francés. Aun concediendo que los testimonios contemporáneos de difusión europea en traducciones múltiples a diversos idiomas puedan resultar hiperbólicos, los datos aportados por L. Astrana Marín (Epistolario, 1946: 769-813) e investigadores posteriores evidencian la fortuna literaria de Quevedo a partir de 1633 y de forma inmediata: los Sueños y el Buscón se vierten al italiano, el francés, el inglés, el alemán y el holandés'; y el Discurso de todos los diablos se traduce en Francia e Inglaterra, donde se edita otra obra lucianesca en versión inglesa, La Fortuna con seso y la Hora de todos. Pero merece la pena detener la atención en otras traducciones de textos alejados de la materia burlesca e insertos en el ámbito moral y político: las versiones italianas de Doctrina moral (1684; Alonso, 2013), Carta a Antonio de Mendoza (1738; V. Nider, 2012 y 2013) y Carta a Luis XIII (1636; L. Barone, 2014); La cuna y la sepultura en holandés (1730, Ámsterdam); y, por su proximidad a Política de Dios, las cinco de Marco Bruto (M. J. Alonso, 2015b), en cuatro idiomas diferentes: italiano (Venecia, 1653), latín (La Haya, 1660; Ámsterdam, 1669), holandés (Ámsterdam, 1700) e inglés (Londres, 1710).

A las versiones mencionadas se suma ahora la francesa de Política de Dios. Juzgadas como conjunto significativo y no meros hechos aislados, permiten aventurar que, en paralelo a la difusión cuantitativamente más relevante de sus textos burlescos (prosa picaresca y lucianesca), existió otra de carácter más «cualitativo» pero no menos relevante, caracterizada no por sucesivas reimpresiones y un éxito popular, sino por una transmisión a través de pequeños círculos intelectuales y de poder, interesados en trasladar a su propia lengua el pensamiento quevediano. Tal vez se halle en este ámbito un pequeño indicio de que Quevedo pudo haber conseguido proyectar, al menos parcialmente, la imagen que había aspirado a legar en el escenario europeo de su tiempo, especialmente en los últimos años de su vida: no la de escritor jocoso, sino la de pensador político y

\footnotetext{
${ }^{9}$ Sobre versiones italianas, véanse B. Garzelli (2011) y V. Nider (2011, 2012 y 2013), acerca de los Sueños y Marco Bruto y la Carta a Antonio de Mendoza, respectivamente; A. Martinengo y D. Símini (2003) sobre el Buscón; y M. J. Alonso (2013) sobre Doctrina moral. Acerca de las francesas, M. Roig Miranda (1997, 2000 y 2011). Las traducciones inglesas fueron estudiadas por D. Arbesú (2006), J. W. Barker (1945) y M. P. Navarro (1987). H. Ehrlicher (2011) se ocupó de la difusión alemana, usualmente a través de versiones indirectas de los Sueños y el Buscón, principalmente.
} 
moral, imbuido de un espíritu humanista ya en vías de extinción ${ }^{10}$. Así parecen confirmarlo traducciones hasta hace poco desconocidas, que animan a replantear la cuestión de la transmisión europea de sus obras, particularmente las ajenas a la esfera burlesca.

\section{Características del manuscrito}

La traducción hasta ahora desconocida de Política de Dios, en concreto de su primera parte, se conserva en una copia manuscrita datada en el siglo XVII. El códice se custodia en la Bibliothèque Municipale Georges Pompidou, en Châlonsen-Champagne, Marne, y tiene asignada la signatura MS 182. La foliación del manuscrito es la siguiente: 2 hojas en blanco, sin foliar +1 folio que contiene la portada en el recto, con el vuelto en blanco +95 folios +1 hoja en blanco. El volumen se encuentra en buen estado de conservación, pese a las huellas ocasionales causadas por insectos. Encuadernado en ternero, se abre sin dificultad y posee unas dimensiones totales de $240 \times 170 \mathrm{~mm}$. El texto ocupa en ambas páginas alrededor de $140 \mathrm{~mm}$. de ancho y $200 \mathrm{~mm}$. de alto. Los márgenes exteriores miden en torno a $20 \mathrm{~mm}$., y los interiores son de unos $5 \mathrm{~mm}$.
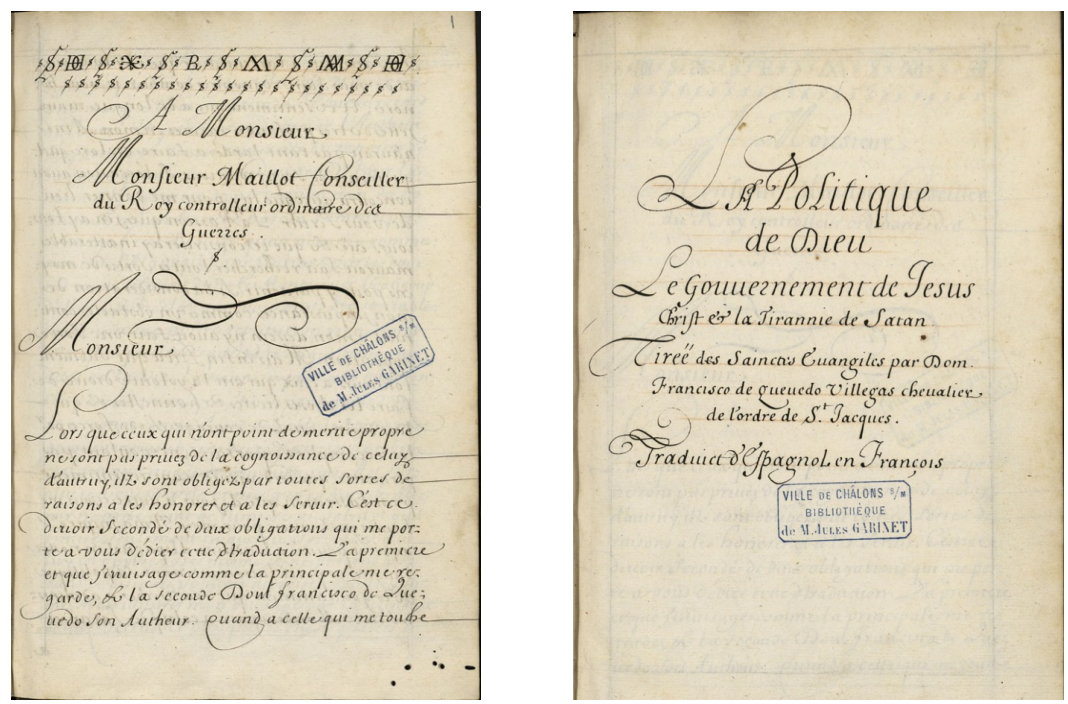

${ }^{10}$ Sobre este asunto, remito a la monografía de A. Rey (2015), The Last Days of Humanism: A Reappraisal of Quevedo's Thought. 

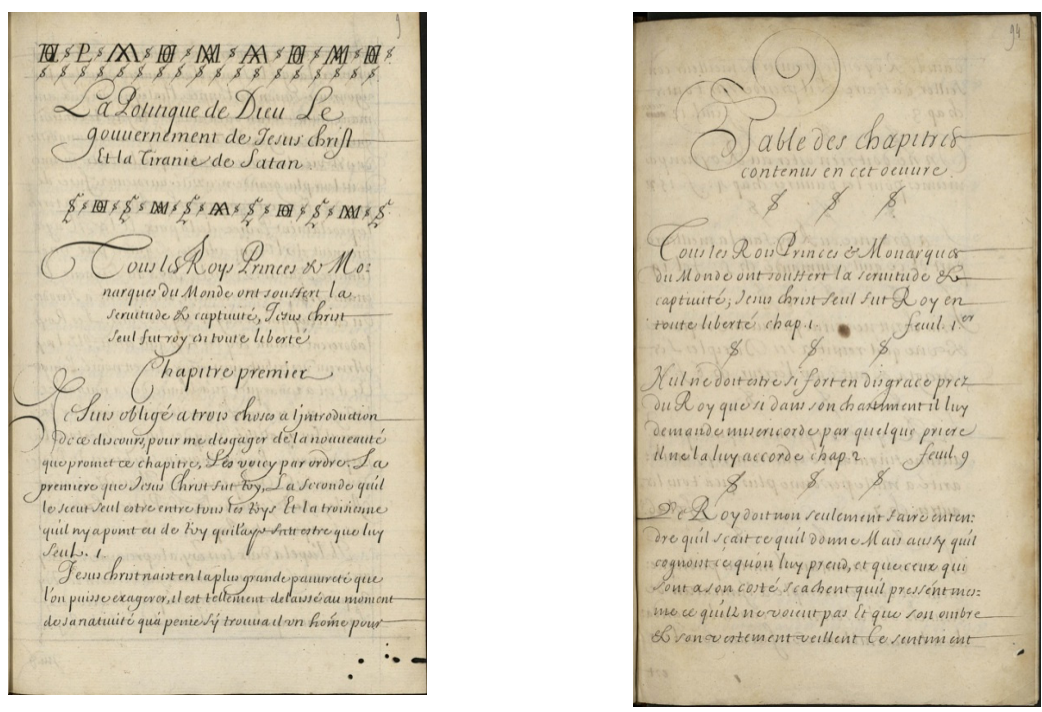

En su portada figura el siguiente título: La Politique / de Dieu / Le Gouuernement de Jesus / Christ \& la Tirannie de Satan / Tiréé des Sainctes Euangiles par Dom / Francisco de Queuedo Villegas cheualier / de l'ordre de S. ${ }^{\mathrm{t}}$ Jacques. / Traduict d'espagnol en François. Debajo del título, está estampado el sello de la biblioteca, con una referencia a quien posiblemente fue su antiguo poseedor: «Ville de Chalons, Bibliotheque de M. Jules Garinet» ${ }^{11}$. En el interior de la portada, se lee la siguiente indicación manuscrita sobre la signatura actual y anterior: «Ms. 182 -. ms. 182.- (Garinet, 13.)»; y un exlibris de la «Bibliothéque de M. J. Garinet», con la anotación también manuscrita «Ms. 13». Tras dos hojas en blanco, la obra comienza con una dedicatoria (ff. 1-2v): «A Monsieur / Monsieur Maillot Conseiller / du Roy controlleur ordinaire des / Guerres».

La copia, que parece realizada por una única mano, tiene el aspecto de una versión definitiva debido a su extremada pulcritud, con adornos en la parte superior de la portada y al comienzo de la obra, así como al final de cada capítulo, y sistemático comienzo de los capítulos en folio aparte. Escrita con letra muy clara y legible en todos los folios, carece casi completamente de tachaduras y utiliza los márgenes para incluir referencias bíblicas insertas en el texto de Quevedo en origen, con la única excepción de una aclaración situada casi al comienzo: en el pasaje que comienza «Así, Señor», «De sorte Sire» (f. 6v), tras la palabra Sire se inserta un

${ }^{11}$ Jules Garinet nació en Châlons-sur-Marne el 18 de agosto de 1797 y murió el 21 de agosto de 1877. Fue abogado en la «Cour royale» de París y «Conseiller de préfecture honoraire», además de escritor e historiador. 
asterisco volado que remite a una nota marginal cuya parte exterior se lee cortada (tal vez debido a la encuadernación): «[C]omme ce discours esté entrepris et [a]dressé au Roy [d']Espagne Le [1]ecteur ne doit [p]as s'étonner si [d]ans la suite il [t]rouue ce mot [de] Sire si fre[q]uenement rei: [ ]teré» (f. 6v, margen izquierdo inferior del folio).

Las correcciones o tachaduras son raras y afectan a segmentos mínimos del discurso (ff. 11, 18, 50v, 51, 58v, 70, 82, 90), con la excepción del f. 69v, donde se tachan y sobrescriben parcialmente tres líneas. Teniendo en cuenta el destinatario de la traducción mencionado en los preliminares propios del texto francés, tal vez se concibió como un precioso regalo a un poderoso vinculado al ámbito de la Corte, aspecto al que me referiré en el análisis de la dedicatoria y el prólogo.

\section{Los preliminares: difusión de la obra de Quevedo en Francia}

La traducción no incluye ninguno de los textos preliminares legales y dedicatorias de la primera parte de Política de Dios en su versión española. En su lugar, copia dos propios, el primero de los cuales es una dedicatoria a un poderoso francés: «A Monsieur / Monsieur Maillot Conseiller / du Roy controlleur ordinaire des / Guerres» (ff. 1-2v), que carece, como el conjunto del manuscrito, de fecha o lugar de escritura explícitas.

Este preliminar aporta datos diversos de gran interés: 1) sobre la posible razón de la traducción; 2) sobre una aparente relación del dedicatario con el propio Quevedo; y 3) sobre la difusión en Francia de otra obra del escritor con anterioridad, útil para la datación aproximada de la versión francesa de Política de Dios. Dos son los motivos que esgrime el traductor, desconocido como sucede en el caso de otras traducciones del tratado político (particularmente las inglesas): «La premiere et que j'enuisage comme la principale me regarde, et la seconde Dom Francisco de Quevedo son Autheur» (f. 1).

Sobre la primera razón aducida, además de las convencionales expresiones de gratitud, cabe destacar la síntesis del tema del tratado quevediano, que remite de modo explícito a la trimembración del título característica de las «versiones primitivas», cuyo último sintagma («tiranía de Satanás») se omite a partir de la primera edición «autorizada» (Madrid, 1626):

Il m'a inspiré aydé et poussé a traduire d'Espagnol en nostre langue ce petit livre continant sa politique et le gouvernement que son verbe a administré in ce monde oposé a celuy de Satan et a sa tirannie. Je vous l'offre non comme un digne payement de ceste affection, mais come une marque de ma gratitude (ff. $1 \mathrm{v}-2)$

Ya como conclusión de la dedicatoria, el anónimo traductor subrayará la condición de «texto piadoso» que justifica su elección para la traducción y su dedicatoria al 
personaje ilustre: «Je conçois cette creance par la cognoissance que j'ay de vostre inclination pour les choses pieuses» (f. $2 \mathrm{v}$ )

En cuanto al segundo motivo determinante de la traducción, la dedicatoria profundiza un poco más en la posible implicación de Quevedo, cuyo agradecimiento habría querido transmitir al destinatario:

Pour le regard de l'autre obligation procedante de l'Autheur. J'ay creu vous devoir remercier en son nom de la peine qu'autrefois vous prisiez de tenir la main a l'impression d'une version d'un de ses travaux mis en françois par un fameux personnage (c'est du livre qu'on nomme communément l'Alguazil d'ont j'intinez parler) qui fut receu et paru dans le Monde avec beaucoup d'estime \& d'éclat par vos soins (f. 2)

La referencia a la impresión de una traducción al francés de una obra conocida popularmente como «l'Alguazil» parece remitir a El alguacil endemoniado, uno de los cinco sueños, que se difundieron conjuntamente, a través de versiones variantes en algún caso fruto de la censura, a partir de 1627, pero con una circulación manuscrita previa muy intensa. Aunque no conocemos una traducción francesa exenta del sueño mencionado, sí existe una conjunta de los Sueños a partir de 1632, en forma de volumen y acompañada por los otros cuatro además de algún apócrifo, con reimpresiones sucesivas: la edición príncipe de La Geneste se publicó ese año en París, a cargo de Pierre Billaine, y contenía, además de los cinco Sueños quevedianos, la espúrea Casa de los locos de amor. En la mencionada versión francesa, origen de múltiples ediciones no sólo en Francia, se incluía en primer lugar aquella a la que podría referirse la dedicatoria de la traducción de Política de Dios, la Vision premiere de l'Algoüazil Demoniaque. A continuación figuraban Vision seconde de la Mort et de son empire, Vision troisiéme du Jugement Final, Vision quatriéme de la maison de foux Amoureux, Vision cinquiéme du Monde en son interieur y Vision sixiéme de l'Enfer (M. Roig Miranda 2000, p. 367, y 2011, pp. 235-237). Ya en el año 1634, la serie de relatos satírico-morales se completó con una séptima «vision», la versión al francés del Discurso de todos los diablos, publicada por vez primera en español en el año 1628.

Si la transcripción es exacta como creo (los trazos de alguna letra inicial resultan confusos y, además, se trata de francés del siglo XVII), el anónimo traductor agradece al dedicatario, en nombre del propio Quevedo, su solidaridad a propósito de una versión al francés de los Sueños, en concreto El alguacil endemoniado, publicada con anterioridad y (es posible deducir) que no habría sido de su agrado. Que el traductor transmita palabras de agradecimiento de un Quevedo aparentemente vivo aún, la temprana difusión de la versión francesa de los Sueños y el hecho de que la traducción al francés de Política de Dios parta de un original que identifico (sin ningún género de dudas, como después explicaré) con las llamadas 
«versiones primitivas» de la obra animan a suponer que el manuscrito se copió quizá no más allá de la década de los años $30^{12}$.

Cabe recordar, además, que El alguacil endemoniado alcanzó una gran popularidad, si se tiene en cuenta que, sólo unas décadas después, generó una imitación con un título coincidente, L'Algouasil burlesque, imité des "Visions" de dom Francisco de Quevedo Villegas, chevalier espagnol, accompagné du «Jardin burlesque» et autres pièces particulières de l'autheur, par le sieur de Bourneuf, escrita por Monsieur de Bourneuf y publicada en París en $1657^{13}$. A esta obra se suman diversas imitaciones del género «sueño» (M. Roig Miranda, 2011, pp. 242243) inspiradas en Quevedo.

El prólogo que sigue a la dedicatoria y sirve de cierre a los textos preliminares ahonda en el contenido y valor de la obra traducida: su importancia para el gobierno de reyes y príncipes o para el comportamiento de ministros y privados; su andamiaje bíblico y su aplicación en la vida real, incluso en el ámbito familiar, de acuerdo con la idea del monarca absoluto como padre de sus vasallos:

qu'on en peut faire quelque cas, non pour son eloquence ny sa maniere de bien parler [...] Mais pour les proffitables enseignemens quil donne pour se conduire suivant les preceptes de Jesus Christ duquel il descrit aussy simplement qui veritablement la Politique et le gouvernement quil exerça durant le temps qu'il conversa parmy les hommes ausquelz et aux roys specialement il enseigne ce qui est de leur dignité, Majesté \& grandeur, les obligations qu'ilz ont de s'en acquitter justement, \& la conformité qu'ilz dovient avoir en toutes leurs actions pour la doctrine du vray Roy Jes. Chr. Il depeinct aux Ministres, Fauoris, Conseillers, \& vassaux leurs soins, charges, \& devoirs par la representation des exemples des Apostres, en sorte qu'ilz n'ont plus besoin que d'en estre les imitateurs. Et pour conclusion il donne a chaque pere de famille beaucoup d'érudition pour vertueusement regir leur petite Republique. Sa lecture ne peut aporter qu'une utilité tres grande a celuy qui la voudras dans la cognoissance qu'elle luy donnera de ce qu'il doit pour suivre \& embrasser comme son bien, fuir \& esuiter comme son

12 De todos modos, los datos editoriales conocidos explicarían que el traductor hubiese tenido acceso al texto no autorizado por Quevedo más fácilmente y mucho tiempo después de su difusión: como recuerda C. Peraita (1997, p. 68, nota 2), «el éxito de la edición primitiva o no autorizada (Zaragoza), en cuya portada se incluía como tercer miembro del título "Tiranía de Satanás", es mayor que el de la autorizada (Madrid); siete de la versión primitiva y dos de la autorizada»; véanse también sobre este asunto J. Moll (1993, p. 10) y J. O. Crosby (1959 y 1966), citados por C. Peraita. Según P. Jauralde (1999, pp. 398-399, n. 2, y 400-401), la obra debía de estar ya redactada entre los años 1618 y 1619, lo que habría podido permitir una intensa transmisión manuscrita previa a la imprenta.

${ }^{13}$ Existen ejemplares, por ejemplo, en la Biblioteca Nacional de Francia y en la municipal de Montpellier. 
contraire l'un et l'autre y estant assez suffizamment expliquez dans la brieveté pour faire naistre l'Amour d'un costé \& l'adversion de l'autre (ff. 3-3v).

El texto de Quevedo se propone así como lectura idónea para quienes ejercen en el ámbito de la Corte, en este caso la de Francia. De hecho, el dedicatario de la traducción, oculto bajo el nombre de «Monsieur Maillot», ostentaba el cargo de «Conseiller du Roy controlleur ordinaire des Guerres». Con indicación precisa de tal título, asociado a dicho apellido, he localizado a un personaje histórico, Gabriel Maillot, cuya actividad se documenta en dos fechas separadas entre sí por tres décadas ${ }^{14}$. La primera de ellas, la que juzgo más relevante para relacionarlo con Quevedo, es el 2 de noviembre de 1635, cuando los archivos nacionales de Francia registran un apunte de naturaleza privada: «Gabriel Maillot, contrôleur des guerres et provincial en Lorraine et Allemagne et Louise Drouet, sa femme, demeurant à Paris rue d'Orléans, paroisse Saint-Jean: donation mutuelle» ${ }^{15}$. La segunda es abril de 1665, fecha de la siguiente indicación relativa a la Gendarmería: «Rolle de la compagnie des Gendarmes de La Reyne-Mère, Rolle de la monstre et teneur faicte aux armées pour la ville D’Amiens le xxbii may 1665 par MrLouis Moreau et Gabriel Maillot conseiller du Roy commissaire ordinaire des Guerres.... D'une compagnie de deux cent hommes des ordonnances du roy sous le tistre de la Reyne

\footnotetext{
${ }^{14}$ No es posible descartar totalmente, no obstante, que el destinatario de la traducción francesa de Política de Dios hubiese sido quien en aquel momento era cabeza del señorío de Maillot, cuyos poseedores pertenecieron durante mucho tiempo a la familia Le Touzey. Se trataría de Jean le Touzey, descendiente de Denis le Touzey, quien fue reconocido noble en el año 1463 y ejerció como comisario del rey Luis XI. Por su parte, Jean le Touzey sirvió durante toda su vida a Luis XIII, con diferentes distinciones, y desempeñó el cargo de teniente de su majestad en varias localidades. Sobre el señorío y la familia Le Touzey, puede consultarse M. de la Chenaye-Desbois, Dictionnaire de la noblesse, 1775, tomo IX, pp. 348349. Acerca de Jean le Touzey, aporta la siguiente información: «ecuyer, seigneur de Maillot, servit presque toute sa vie avec distinction sous Louis XIII, fut Lieutenant pour Sa Majesté des Villkes \& Château Trompette, Bordeaux, Cherbourg \& Domfront (p. 349). A continuación, proporciona datos sobre sus descendientes. Pero, como se observa, en ningún momento se cita que hubiese desempeñado el cargo de «contrôleur des guerres».

${ }^{15}$ Archives Nationales, Paris Fontainebleau Pierrefitte-sur-Seine, Châtelet de Paris, Y//173Y//177, insinuations (12 avril 1633-17 août 1637); insinuations Y//175, dates des insinuations: 23 mars 1634-1er décembre 1635, notice $\mathrm{n}^{\circ}$ 5016, date de l'acte: 2 novembre 1635 (par É. Campardon, Ch. Samaran, M.-A. Fleury et G. Vilar). El registro y su transcripción están disponibles en: https://www.siv.archivesnationales.culture.gouv.fr/siv/rechercheconsultation/consultation/ir/consultationIR.action;jse ssionid=438116A72823CFDAC5E58BD6BBF24D36?udId=d_3_1048\&irId=FRAN_IR_00 5816 (consultados el 14 de enero de 2015).
} 
mère» ${ }^{16}$. A este personaje podría referirse asimismo el cardenal Richelieu en sus Memorias correspondientes al año 1627, aunque el uso exclusivo del apellido, sin el cargo, hace más complicada su identificación ${ }^{17}$.

En el ámbito bibliográfico, Gabriel Maillot consta como autor de dos publicaciones fechadas en 1674 y 1676: Factum pour Mes Gabriel Maillot, contrôleur ordinaire des guerres, et François Foubert, chirurgien ordinaire de feu $M$. le duc d'Orléans, tant en son nom que comme légitime administrateur des biens de ses enfants, donataires de Jérôme de Bragelogne [...] appelants d'une sentence de messieurs... (Journet, 1674); y, de carácter polémico contra el célebre filósofo y metafísico, historiador y abogado Géraud de Cordemoy, Factum pour Mes Gabriel Maillot, conseiller du roi, contrôleur ordinaire des guerres, et Henry Drouet, secrétaire de M. de Sève, maître des requêtes [...] contre maître Géraud Cordemoy, avocat en parlement... (Nezan, 1676).

Los datos existentes sobre el poderoso de la corte francesa a quien habría sido dedicada la traducción de Política de Dios apuntan también a que la versión francesa podría haberse redactado en un período tal vez temprano, el de coincidencia entre la difusión europea de Política de Dios aun en vida de Quevedo y la labor de Maillot como responsable de Guerra del monarca francés: la etapa comprendida entre finales de la década de 1620 o principios de la de 1630 y la década de la muerte de Quevedo (1645), que es también la del fallecimiento de Luis XIII de Francia (1601-1643). Aunque no he podido hacerlo por el momento, resultaría sin duda muy interesante llegar a establecer documentalmente alguna relación entre Quevedo y Gabriel Maillot.

\footnotetext{
${ }^{16}$ El documento se refiere a la «Compaigne des Gendarmes de la Reyne-Mere, Maison du Roi-Gendarmerie y, localizado por Jean-Pierre Herriau y Sébastien Jourdain, procede de la Bibliothéque National, FR 25868, p. 1021. El documento completo puede consultarse en el siguiente enlace:

http://www.ancestramil.fr/uploads/01_doc/terre/milices_et_gendarmerie/1620$1789 /$ cie gendarme reyne mere $166 \overline{5}$.pdf (consultado el 14 de enero de 2015).

${ }^{17}$ El pasaje aludido es el que sigue: «et que, si Maillot, qu'elle y avoit dépêché à cette fin, eût été arrivé, S. M. ne croyoit pas qu'il eût donné ordre de demander justice contre Bourbonne; qu'elle ne pouvoit faire autre chose que d'écrire au Roi ce qui se passoit» (cito por Richelieu, Memorias, 1926, p. 228). De hecho, el editor introduce una nota identificándolo con Jean Le Touzey, el noble al que he citado previamente como uno de los posibles referentes de la expresión «Monsieur Maillot»: «Peur-être Jean Le Touzey, seigneur de Maillot, lieutenant du Roi à Château-Trompette, Bordeaux, Cherbourg, Domfront. Les Mémoires écrivent Maillau» (p. 228, n. 1).
} 


\section{El texto de partida: las versiones primitivas}

Dada la complejidad textual de la primera parte de Política de Dios, una obra con una intrincada transmisión textual manuscrita e impresa y versiones variantes, resulta conveniente identificar a cuál de ellas pertenecía el texto del que partió la versión francesa, antes de proceder al análisis de la traducción localizada ${ }^{18}$. Aunque tal tarea puede aportar sólo resultados aproximados, orientativos, debido a que los cambios consustanciales a cualquier proceso traductor oscurecen siempre los perfiles del original de partida, existen ciertos indicios, relativos sobre todo al título y a la disposición de capítulos, que permiten afirmar que el anónimo traductor francés contó con un testimonio de las llamadas «fuentes primitivas» o no autorizadas explícitamente por Quevedo ${ }^{19}$.

a) El título. La traducción francesa porta un título tripartito, La politique de Dieu, le gouvernement de Jesus Christ et la tirannie de Satan, coincidente con el de las «versiones primitivas», en cuyas portadas se lee: «Política de Dios, gobierno de Cristo y tiranía de Satanás». El rápido éxito cosechado por la obra no estuvo exento de polémica, con consecuencias directas sobre su título y su texto: las reacciones contrarias inmediatas, como la de Morovelli de Puebla, apoyadas con posterioridad por las invectivas de Pacheco de Narváez o Juan de Jáuregui, debieron de influir en la eliminación del tercer miembro del período en las dos primeras ediciones

\footnotetext{
${ }^{18}$ Sobre la tradición textual de la obra, la filiación y las variantes de sus testimonios, remito a la información de J. O. Crosby (1959 y 1966) y E. Díaz (2012, pp. 161-184).

19 Todo mi análisis se basará en los completos estudios textuales que acompañan a las ediciones de J. O. Crosby (1966) y, más reciente, E. Díaz (2012), así como en la consulta de los testimonios esenciales de la obra, particularmente el manuscrito Frías, además de la primera edición no autorizada de Zaragoza (1626) y la princeps autorizada de Madrid (1626), con cambios notables, determinados, entre otras razones, por invectivas como las Anotaciones a la Política de Dios, gobierno de Cristo y tiranía de Satanás, escritas por Francisco Morovelli de Puebla en el propio año 1626. Los testimonios de época tomados en consideración son: Política de Dios, gobierno de Cristo, Madrid, viuda de Alonso Martín, a costa de Alonso Pérez, 1626 (primera edición autorizada), ejemplares: Hispanic Society of America, biblioteca de James O. Crosby, y Biblioteca Nacional de España, con signatura R/7796; Política de Dios, gobierno de Cristo, tiranía de Satanás, Zaragoza, Pedro Verges, a costa de Roberto Duport, 1626 (primera y segunda edición), ejemplares: Hispanic Society of America, biblioteca de James O. Crosby (primera), y Biblioteca Nacional de España, con signatura R/11546 (segunda); Política de Dios, gouierno de Cristo y tiranía de Satanás, manuscrito «Frías», ms. B2905 de la Hispanic Society of America. Véase también M. Gendreau (1977, pp. 181-196), quien compara los pasajes retocados o suprimidos.
} 
«autorizadas» de la obra (Madrid, 1626), que titulan Política de Dios, gobierno de Cristo, con omisión de toda referencia a Satanás ${ }^{20}$.

b) Número y orden de capítulos. Las distintas versiones de Política de Dios numeran y distribuyen los capítulos de diferente modo: en el caso de las fuentes primitivas, el número oscila entre los 21 del manuscrito «Heredia Spínola» y los 20 del manuscrito «Frías» y las impresiones de Zaragoza en 1626; por su parte, las ediciones «autorizadas» por Quevedo, dos publicadas en Madrid en 1626, incorporan tres nuevos capítulos, que ocupan la posición 11, 12 y 14 en el conjunto, lo que provoca una recolocación del resto y una definitiva cifra total de $24^{21}$. Como la versión francesa está estructurada en 20 capítulos, cabe suponer que pudo derivar de alguna de las versiones primitivas, a excepción del manuscrito «Heredia Spínola», pues comparte con ellas también el orden de los distintos apartados. Pero deben tenerse en cuenta otras coincidencias que refuerzan esta conclusión, en concreto la que afecta al texto rotulado en las ediciones autorizadas como «capítulo 1»: como apuntó J. O. Crosby (1966, p. 358), en las primitivas, concretamente en el manuscrito Frías y en las ediciones de Zaragoza, «este capítulo se coloca primero, pero no se denomina capítulo, ni lleva número (el capítulo segundo está numerado

${ }^{20}$ Cabe recordar, en este sentido, algunas referencias de Morovelli de Puebla al título en sus Anotaciones (1626): «Yo, movido de la novedad del título [...] deseaba vella [...] El título Política de Dios, Gobierno de Cristo, Tiranía de Satanás, grandioso, misterioso, sentencioso, promete grandezas, misterios, sentencias [...] El título tresdoblado, y, como Trismegisto, tres veces grande, y el libro aun no vale por uno [...] hubiéralo acertado el autor en haber publicado el título sin el libro, por la expectación que de él se cobrara [...] Alabemos con admiración el título, que lo merece su grandeza, y aguardemos a ver si una causa tan pequeña se sale por una tan ancha entrada. También pican en el título, pareciéndoles que, ya que contraponía a los dos primeros [el gobierno de Dios y el de Cristo], lo tercero venía más a cuento decir: Tiranía del mundo, cuyas leyes y gobierno son tiránicos, violentos, voluntariosos [...] Y dijo uno que aunque no fuera sino por no comenzar luego al principio con el Malo (Dios nos libre), no lo debiera mentar» (pp. 986-987). El título trimembre completo también se cita en el Memorial de Pacheco de Narváez «denunciando al tribunal de la Inquisición cuatro libros de D. Francisco de Quevedo» (1630), donde alude a la reescritura de la obra: «Y advierto [...] que este libro se volvió a imprimir [...] con nombre corregido y emendado, y que, a mi parecer, lo está tan poco que obliga a no menor cuidado que el primero» (p. 1046). También Juan de Jáuregui discrepó del primer título en El retraído (1635), «Aun en el título de su Política puso luego a Satanás junto a Cristo» (p. 1074). Sobre este asunto, véanse A. Fernández-Guerra (1946, p. 4) y M. J. Alonso (2015a).

${ }^{21}$ En todas las primitivas faltan los capítulos 11 y 12; el 13 es el décimo en ellas, salvo en el manuscrito «Heredia Spínola»; el 14 también falta en todos ellos; en cuanto al 15, es el 11 en las primitivas, salvo en el caso del manuscrito antes mencionado, donde es el 12; de este modo, el 16 es el 12, y así sucesivamente (uno más en HS). 
como el primero, y los otros siguen sucesivamente)». Lo mismo sucede en la traducción francesa, que tuvo que hacerse a partir de alguna de ellas.

c) Textos preliminares y tabla final de capítulos. Menos precisos resultan los datos que se extraen del cotejo de esta parte de la traducción respecto a las distintas versiones de Política de Dios. Esta obra se difundió con una dedicatoria en la portada al Conde-Duque de Olivares y numerosos textos preliminares, compartidos mayoritariamente por las versiones primitivas, aunque con ciertas peculiaridades en el manuscrito «Heredia Spínola» ${ }^{22}$ : la aprobación de Esteban de Peralta; la licencia de Juan de Salinas; la aprobación de Mendoza; la dedicatoria a Olivares; el prólogo «A quien lee»; la carta «El librero al lector» antes citada, que da cuenta de traducciones al francés e italiano; la carta de don Lorenzo Vander Hammen a Quevedo; citas de Proverbios 6 y Eclesiastés 10; «Pregón y amenaza de la Sabiduría», «Palabras de la verdad», «A los hombres»; y «Dedicatoria a Felipe IV». La traducción francesa parece deslindar dos tipos de preliminares diferentes entre los citados: por un lado, los elogios o las dedicatorias; por el otro, las citas o exhortaciones de contenido bíblico más directamente atenidas al contenido de Política de Dios. De hecho, elimina los primeros por completo, sustituyéndolos por los nuevos ya citados, y traduce todos los que siguen a excepción de la «Dedicatoria a Felipe IV», lógicamente inapropiada en un códice pensado para su difusión en Francia, aunque ha de tenerse en cuenta que ni «Frías» ni las ediciones de Zaragoza la incluyen ${ }^{23}$. La distinción entre los dos tipos de preliminares se plasma de un modo gráfico en el manuscrito «Frías», donde un folio en blanco separa los primeros de lo que considera auténtico comienzo de la obra, las citas bíblicas, con el título «Proverbiorum» (f. 1), en el primer folio numerado. Finalmente, el manuscrito «Frías» y las ediciones no autorizadas concluyen con una tabla del contenido, que relaciona el epígrafe y el folio de los 20 capítulos, también incorporada en la traducción francesa.

d) Variantes del texto. Descartadas las ediciones autorizadas como texto de partida, el cotejo de la traducción francesa con las variantes de las versiones primitivas de la obra evidencia que el manuscrito «Heredia Spínola» es el único de ellas que no pudo servirle como modelo: no contiene ninguna de sus abundantes variantes privativas y, por el contrario, su texto es siempre coincidente con el de los otros testimonios del grupo. Se aporta un ejemplo muy significativo, entre los muchos que se podrían aducir, en el que se observa cómo la traducción contiene un largo pasaje omitido en la edición madrileña de 1626 y cómo la versión resultante está menos cerca de «Heredia Spínola» que de las otras versiones primitivas:

\footnotetext{
${ }^{22}$ Este manuscrito, que tiene dos dedicatorias a Felipe IV, no copia la de Olivares ni tampoco la carta de Lorenzo Vander Hammen a Quevedo.

${ }^{23}$ Estas versiones sí tienen la dedicatoria a Olivares. Las ediciones autorizadas cuentan con la dirigida al monarca.
} 


\section{Y aunque (ediciones autorizadas)}

Por este error que tanto sabe a tierra en el libro del talmud Berachot, quiere decir: 'de las bendiciones', capítulo Henundim 1: «No estarán, dice rabí Eliazar; desde el día que el templo se destruyó [espacio en blanco] de la oración se cerraron. Así lo dice Ieremías, templo enterrado Cristo, Thren.; y aunque es verdad que las puertas del cielo se cerraron a las oraciones de los judíos, mas las puertas de la conversión en todo tiempo están abiertas. Léese en el Talmud Medrastillim, donde dice rabí Samuel Barranchina: «las puertas de la oración alguna vez se cerraron, y algunas se abrieron, como se ve cada día». Mas Sarey Tesuba: «las puertas de la conversión nunca se cierran». Y aunque (Heredia Spínola)

Por este error que tanto sabe a tierra en el libro del talmud Berachot que quiere decir: 'de las bendiciones', capítulo Henundin. Dice el hebreo Sarei Tefilo: «las puertas de la oración se cerraron». Así lo dice Ieremías, Iere- mías, Thren. 3; y aunque es verdad que las puertas del cielo se cerraron a las oraciones de los judíos, mas las puertas de la conversión en todo tiempo están abiertas. Léese en el Talmud Medrastillim, donde dice rabí Samuel Baranchina: «las puertas de la oración alguna vez se cerraron, y algunas se abrieron. No se ve cada día». Mas Saray Rabusa: «las puertas de la conversión nunca se cierran». Y aunque (Frías y ediciones no autorizadas, con algunas variaciones)

depuis le jour que le temple fut destruit Sarey Hebreu dit que les portes de l'oraison furent firméés. Ainsy lo dit Hieremie en ses thrénes c'est a dire Lamentations [al margen: chap. 3. vers. 44] Et quoy qu'il soit veritable que les portes du ciel furent fermeés aux oraisons des juifs. Les portes de la conversion sont neantmoins ouuertes en tout temps. Il se lit en Rabi Samuel Hebreu que les portes de l'oraison se sont quelque fois firmées, \& quelque fois ouuertis, cela ne se vuit pas chaque iour. Mais Sarey Rebuza dit que les portes de l'oraison ni si ferment iamais. Et qu'encor que (Le politique de Dieu, f. 11v)

Este pasaje refleja una considerable omisión de las versiones autorizadas respecto a las primitivas, a las que sigue sin duda la traducción francesa, salvo por la eliminación de la secuencia inicial («Dice el hebreo Sarei [...] nunca se cierran»).

Si bien no parece posible identificar de modo tajante cuál de ellos estuvo en el origen de la versión al francés, existen algunas coincidencias con el manuscrito «Frías»:
a persuasión del cielo (Zaragoza)
a persuasión del celo (Heredia Spínola, Frías)
a la persuasion de son zele (Le politique de Dieu, f. 37)
y tentador es // om. (Frías, Politique de Dieu)

La lectura cielo es error presente en las ediciones no autorizadas de Zaragoza; la traducción lee correctamente celo, como lo hacen los manuscritos primitivos y las 
impresiones autorizadas. El segundo caso invita a pensar en «Frías» como origen de la versión francesa: todos los testimonios leen «Satanás y tentador es que haga de las piedras pan», salvo el citado manuscrito, que omite «y tentador es», secuencia también elidida en la traducción.

A las lecturas comunes puede sumarse otra variante de interés: el manuscrito francés cierra la obra, antes de la tabla final, con la fórmula «Louange a Dieu», traducción de «Laus Deo», incluido en todas las versiones primitivas salvo «Heredia Spínola»; y, frente al resto de testimonios, que después de la tabla incluyen diferentes expresiones con datos de imprenta o lugar, tanto «Frías» como la traducción concluyen con un escueto «fin»/ «finis». Otras coincidencias se refieren a la división en párrafos, muy similar en amplios pasajes como los capítulos 5, 15 o 19, y especialmente en el capítulo segundo, constituido en ambos casos por un único párrafo de principio a fin.

No cabe duda de que el traductor francés se sirvió de alguna versión primitiva de Política de Dios. Pero debe reconocerse que precisar cuál de ellas fue, con exactitud y sin posibilidad de error, resulta imposible ${ }^{24}$. Sobre todo porque algunos datos resultan desconcertantes y revelan que, o bien se usó ocasionalmente un ejemplar de la edición autorizada, o bien se obró con diligencia corrigiendo algún error presente en las versiones no autorizadas o completando alguno de sus datos. Así sucede con la adición «Je dors \& mon coeur veille» (f. 28v) respecto a «Yo duermo, \&» de todos los testimonios, que coincide con la cita íntegra aportada por «Heredia Spínola», aunque no habría hecho falta consultar este manuscrito para completar la referencia. En otro caso, la traducción corrige un error en una referencia bíblica de las versiones primitivas, en coincidencia con las autorizadas, pero habría sido muy fácil la enmienda para un traductor con una cultura religiosa media $^{25}$ :

una al templo para que le adorase, y otra al monte para que se despeñase [...] los llevan al desierto, para que sean tentados; al templo, para que los adoren a ellos; no al templo, al monte para que se despeñen (versiones primitivas)

\footnotetext{
${ }^{24}$ La traducción pudo haber partido de testimonios hoy desconocidos; incluso, suponiendo que Quevedo no hubiese permanecido ajeno a la versión francesa como parece apuntar la dedicatoria, podría haber entregado al traductor una copia manuscrita, tal vez la «copia hipotética con ciertos cambios» que J. O. Crosby (1966, p. 343) identifica como ß en su stemma de la primera parte de Política de Dios, al igual que E. Díaz (2012, p. 179), en referencia a una «versión preparada para la edición», de la cual habrían partido «Frías» y la primera edición no autorizada de Zaragoza.

${ }^{25}$ La corrección se reitera más adelante: donde las versiones primitivas leen, con error, «y echarse del monte» (salvo «Heredia Spínola»: «echarse del templo»), la traducción francesa copia «\& se jetter du haut du pinacle du temple» (f. 84) para un pasaje convertido en «echarse del pináculo» en las ediciones autorizadas.
} 
una al templo para que se despeñase y otra al monte para que le adorase [...] al templo para que se despeñen, al monte para que los adoren (ediciones autorizadas)

une sur le temple a fin quil s'en precipitast \& l'autre en la Montagne a fin quil l'adorast [...] les conduient, au desert afin quilz soient tintiz, au temple afin qu'ilz se jettent du haut en bas (Politique de Dieu, f. 76v)

Del mismo tipo puede considerarse el caso en que la traducción lee correctamente «au chap. 20 des Actes des Apostres» (f. 79v), como las ediciones autorizadas y «Heredia Spínola», en lugar de «capítulo 22», en el resto de las versiones primitivas. Dado que el traductor muestra un apreciable conocimiento bíblico, pues completa alguna referencia, cabe interpretar que la corrección pudo producirse sin la necesaria mediación de las ediciones autorizadas, si es que no se basó en otro testimonio hoy desconocido.

\section{Características de la traducción}

La pulcritud caligráfica de la traducción va acompañada de una llamativa fidelidad al original, inusual si se compara con ciertas versiones de las obras burlescas de Quevedo publicadas en Francia, particularmente las del Buscón y los Sueños $^{26}$. Existe un respeto absoluto al contenido de la primera parte de Política de Dios, en su estructura general de 20 capítulos (en las versiones primitivas) con sus respectivos epígrafes, en su orden y en el contenido de cada uno de ellos; en sus preliminares basados en la Biblia; en su tabla final; y, como se comentará en este apartado, también en el propósito y el sentido de todos los pasajes, salvo muy contadas excepciones. Las intervenciones del traductor, que permiten encontrar abundantes ejemplos de cambios correspondientes a todas las categorías modificativas, conllevan no obstante muy leves consecuencias para el conjunto, inalterado en su integridad de forma y contenido, aunque salpicado de numerosas adiciones y omisiones.

a) Supresión de citas bíblicas latinas. Entre las modificaciones practicadas en la traducción debe comentarse en primer lugar, por su carácter sistemático, la omisión de los textos latinos. Aunque su desaparición supone la ausencia de muchos textos, algunos de gran longitud y especialmente al comienzo de los capítulos, el texto quevediano no pierde nunca su sentido completo: como Quevedo suele aportar la cita latina y la glosa española a continuación, por partida doble, el

\footnotetext{
${ }^{26}$ Pueden consultarse los comentarios de M. Roig Miranda (2000 y 2011) sobre las ediciones francesas de los Sueños y también sobre las de otras obras, especialmente el Buscón, afectado por cambios de gran calado practicados por La Geneste especialmente en el final del relato picaresco, respectivamente.
} 
traductor se limita a una única versión de la misma, siempre en francés, porque tal duplicidad debió de parecerle redundante.

Pero debe notarse la existencia de algún caso en que la inclusión de la cita una única vez en el original (en latín o en español) desemboca en una omisión completa de la misma en la traducción:

Con estas palabras habló elegante la caridad de San Pablo: Roman. 5. Ut quid enim [...] mortuus est // Sur ces paroles la charite de S. Paul a parlé elegamment escriuiant aux Romains (f. 19v; al margen añade: «chap. 5.»)

Non quia de egenis, pertinebat ad eum // om. (f. 24)

Domine memento mei // om. (f. 50)

Otras veces el segmento eliminado es también la introducción previa a la cita latina, como sucede en el siguiente ejemplo: y Cristo en la borrasca, donde enseñó durmiendo. Ioan. cap. 18. Simon ergo Petrus [...] desteram // om. (f. 27). Y la ausencia de las citas latinas y las referencias bibliográficas genera en ocasiones una lógica modificación del encabezamiento del pasaje: Ioan. c. 5. Angelus [...] aqua // L'Evangeliste poursuit \& dit (f. 68).

b) Omisión de referencias en epígrafes. La versión francesa elimina todas las indicaciones a los libros, capítulos y versículos bíblicos, incluidos en el original español por lo general al final del epígrafe de los distintos capítulos. Más que omisiones, se trata de traslados de la información a los márgenes del folio, si bien en algún caso este trasvase no es completo y se pierde algún fragmento de la cita. Así, por ejemplo, un epígrafe omite en la traducción las referencias bíblicas que le sirven de cierre - «Math. 14, Ioan. 6. Marc. 6. Luc. 9.» (f. 21v)-, introducidas al margen a excepción de la de san Juan, eliminada totalmente; y la información del epígrafe del capítulo 18 no se inserta en el espacio marginal, omitiéndose en su integridad.

Raramente se registra alguna omisión en una referencia integrada en el texto y no en los epígrafes:

Mat. 12 // om. (f. 26)

San Pablo lo dice en el Act. Apost. cap. 20 // Aux actes des Apostres il dit di soy (f. 66)

2. Cor. 11. cap. 23 // escriuant aux Corinthiens dit (f. 66)

les dice por san Juan, cap. 14 // Il leur dist (f. 86)

c) Adiciones. Son muy frecuentes y por lo general afectan a palabras o frases cortas. Sus propósitos se pueden resumir en dos fundamentales: precisión y 
amplificación. En lo que respecta al primer caso, pueden añadirse ordinales en las partes de una argumentación, marcando mejor el desarrollo del discurso ${ }^{27}$ :

que fue rey Jesucristo, que lo supo ser solamente entre todos los reyes, que no ha habido rey que lo sepa ser sino él solo // La premiere que Jesus Christ fut roy, La seconde qu'il le sceut seul estre entre tous les Roys Et la troisieme qu'il nya point eu de Roy qu'il ay estre que luy seul (f. 9)

El que se descuida // Celuy au contraire qui se neglige (f. 25v)

se representaron la desnudez y miseria // nous a esté representé deux choses. La premiere l'jndigence \& misere (f. 56)

que el rey // La premiere que le roy (f. 70)

tendrá virtud, y de otra mano veneno y muerte // tiendra la vertu d'une main \& le venim \& le mort de l'autre (f. 70)

En los numularios y logreros [...] En los que venden palomas // Les troisiesmes furent les compteurs \& changeurs [...] Les quatriesmes ceux qui vendoient les pigeons (f. 73)

El postrer negocio // la troisiesme negociation (f. 83)

que en las dos proposiciones // qu'aux deux propositions premieres (f. 84)

En otras ocasiones se especifica algún dato no explícito, sino implícito o mencionado ya en el contexto, como cuando se añade un sujeto elidido («le prince», «ses disciples», «Jesus Christ», «Adam», «la fillette», «vassaux», «la mere», «le texte», «le diable», «les hommes») o se hace una precisión, incluso valorativa a través de un adjetivo.

determinó de bajar en una de las personas a gobernar el mundo // Il determina de descendre in une des personnes de la saincte trinité pour regir le monde (f. 6)

y preguntan a Herodes // Et estans arrivez in Hierusalem, demandent a Herodes (f. $9 \mathrm{v}$ )

y al morir le inscribieron rey // et a celle de sa mort sur la croix il fut qualiffié Roy des Juifz (f. 9v)

\footnotetext{
${ }^{27}$ Dada la abundancia de ejemplos y en aras de la brevedad, en este apartado incluiré sólo algunos de los más significativos. Para el cotejo y la exposición de los casos seleccionados, y dado que es posible descartar las autorizadas como original para la traducción, me he basado siempre en las lecturas de las versiones primitivas, aunque sin precisar los leves cambios que existen entre ellas. Marco en cursiva el segmento afectado por la intervención del traductor.
} 
mas escureciéronsele todas en el sol y la luna // mais di plus elles furent toutes obscurcies dans l'eclipse du soleil et di la lune (f. 10v)

Jesús, hijo de Dios // Jesus filz du soumerain Dieu (f. 17)

que le hizo otras preguntas // Jesus Christ luy fit quelques demandes (f. 17)

y de criados a los primeros atrevimientos pasan a señores // qu'aux prémieres enterprises temeraires telles sortes de Ministres veulent passer pour souuerains (f. 23)

El que quita // Celuy qui pour quelque raison que ce soit oste (f. 24) para él // pour son Maistre (f. 24)

En los peligros, en rey que mira manda con los ojos // Le roy que contemple ses soldats dans les perilz, leur comamnde avec les yeux (f. 27)

con las órdenes // par les ordres escrits (f. 27)

uno entre tantos // un entre plusieurs soldat (f. 27v)

su padre // pere eternel (f. 35)

Cristo y Juan // Jesus Ch. et C. Jean Baptiste (f. 42)

de la sed en la samaritana, que se cansa: Casatus ex itinere // de la soi quand il demanda aboire a la Samaritaine qu'il se lassa (f. 47)

el ladrón // le bon larron (f. 50)

Fue condenar al cuchillo a Jacobo, y a la tina a Juan // Ce fut les condamner se auoir Jacques a mourir d'un coutelas et Jean a estré jetté en la chaudiere d'huyle (f. 53)

Estaban rendidos al sueño Pedro y los que con él estaban // Pierre \& ceux qui estoient auec luy au Tabor soubmis et abandomiez au sommeil (f. 54)

sabía estimar // sçauoit estimer l'honneur (f. 62)

bien introducidos están con la absolución // sont jntroduit aux sacremens, qu'ilz reçoiuent des absolutions (f. 71v)

aquí y al güerto // a la transfiguration \& au jardin (f. 76v)

El ministro // Le ministre pervers (f. 83)

fue la causa Ramoth Galaad // pour raison d'une ville apeléé Ramoth Galaad (f. 87)

y respondiole a él // Et le texte dit qui Micheas respondit au Roy» (f. 88)

Oh providencia de Dios // O sage providence de Dieu (f. 92v)

Pero existen casos en que la adición, también clarificadora y explicativa, afecta a secuencias más extensas:

sic volo, sic iubeo, sic pro ratione voluntas; así lo quiero, así lo mando, valga por razón la voluntad // Aynsi ie le veux, Ainsy ie le commande, suma volunté est 
ma raison, n'obscurcira point leur nom, ny leur memoire. Le Monde est tant encor dans son principe (f. 7)

más ejecutiva es la muerte con el que priva que con el fratricida // On tollere mieux la morte de celuy qui est en favour, et elle est estiméé mieux executéé, que celle qui priuient de la main d'un fratricide (f. $7 \mathrm{v}$ )

hallar gracia con los reyes de la tierra acarrea temor; sólo con Dios es seguro; así dijo el ángel // La grace que l'on rencontre ches les Roys de la terre est tousiours suiuie de cramte. Mais celle que l'on trouve avec Dieu n'est promit sujette a l'instabilité de la fortune aynsy que lismoigna. L'Ange disant (f. 8)

Nace en la pobreza más encarecida, apenas con aparato de hombre // Jesus Christ naist en la plus grande pauverté que l'on puisse exagerer, il est tellement delaissé aun moment de sa natiuité qua penie s'y trouua il un home pour tout aparat (ff. 9-9v)

Queréis que dé libertad al rey de los judíos [...] gritaron otra vez // Voulez vous que ce relasche le roy des juifs et ilz crierent sy tu luy donnes la liberté tu n'es pas amy di Cesar (f. 10)

teniendo bolsas traía lo que daban // lo que tenant la bource il auoit la distribution des choses qu'un donnoit pour subuenir aux necessiteux (f. 23v)

y en los vasallos asistidos de su señor es diferente el ardimiento // Et la hardiesse est differente entre les vassaux assitiz de leur seigneur \& ceux qui en sont separez (f. 27)

Responde el apóstol // L'Apostre sans beaucoup exammier son discours, ny peser ses paroles respond (ff. $29 \mathrm{v}-30$ )

obligarán a que venga Dios a desagraviar los desvalidos // Ilz obligeront Dieu a venir pour soulager les foibles \& secourir ceux qui sont sans suport (f. 69)

El rey es camino, claro está, y verdad y vida. Pues ¿cómo podrá ser que el camino siga al caminante // Il est evident que le roy est la voye la verité et la vie or le roy estant la voye, les ministres sont ceux qui ycheminent \& silz menent le roy comment se pourra il faire que la voye suiue le voyageur (f. 75)

se atreve al cuidado de Dios // il entreprend sur le soin de Dieu qui s'est reserué celle des roys (f. $75 \mathrm{v})$

para que se despeñase // a fin quil se precipitast sans un grand dessein (f. 83)

tenerle en poco, despreciarlo, que el rey ruegue // Ces jmpudences ne marquent elles pas quil n'a aucune reuerence pour son prince quil le mesprise, que le roy prie (f. $83 \mathrm{v}$ )

Como se observa, aunque la adición es mayor, no se produce un cambio en el sentido del pasaje, sino que se añaden consideraciones o circunstancias que de algún modo se pueden extraer del texto o resultan en cierta medida redundantes. 
El segundo de los principales propósitos comentados consiste en amplificar, o construir si no existe ya, una serie de miembros con un efecto fundamentalmente intensificador:

las glorias de Dios // les triumphes \& les gloires d'un Dieu (f. 10)

tuvieron maestro resplandeciente // Ilz aurent un maistre radieux \& resplandissant (f. 10v)

y atemorizó los escribas cuando le prendieron militó aun las palabras, preso respondió con el silencio, crucificado reinó en los oprobrios; muerto, ejecutorió el vasallaje que le deben el sol y la luna // quant l'aborda pour le prendre $n i$ se seruant poor toutes armes que de la seule parole, il fit trembler les scribes \& les Boureaux \& leur fit mesurer la terre, estant pris il respondit avec le silence, crucifié il regna dans les oprobres. Mort, il receut l'hommage que luy deuoient le soleil, la lune, les estoiles et les elements (f. 12)

La calumnia, que es de bajo linaje // la calumnie qui est de basse et vile espece (f. 21v)

gran voz // voix forte \& grande (f. 26v)

que tengan bolsones // qui gouuernent \& tiennent la bource (f. 26v)

Los unos sustenta el enemigo // Los unes resistent \& soustiennent l'ennemy (f. 28)

aquellas palabras tan esforzadas de la fe // ces paroles de foy si fortes et vigoreuses (f. 32)

la ahondan y ensanchan // l'jrrite, l'enflame, et l'augmente dauantage (f. 34)

la hacienda // les biens \& les richesses (f. 37)

El recato // La finesse \& la cautelle (f. 42)

nuestra diligencia // nostre soin \& dilligence (f. 42v)

mudos para responder // muet $\&$ san paroles por respondre (f. 46v)

la cabeza inclinada mal enderezará los miembros // la teste enclinéé addressera $\&$ conduira mal lis membres (f. 48)

de las caídas de los privados // des cheutes \& renuersement des fauoris (f. $52 \mathrm{v}$ )

ajustada proposición // proposition esgale \& raisonnable (f. 54v)

sino crudamente // d'une façon rude \& gros (f. 54v)

los ánimos más puros // les plus nettes et meilleures ames (f. 57)

Esto hablo así para nuestras costumbres // Je parle de cette façon a les gard de noz moeurs \& de noz coustumes (f. 57v)

en el modo de darla // dans les moyens \& forme de les donner (f. 58)

señor de todo // signeur \& maistre de tout (f. 63v)

que clama en poblado // qui crient dans les villes \& bourgades (f. 65)

el que es descamino y mentira es muerte // Celuy qui va errant ça \& la \& qui est adorné au mensonge est la ruine et la mort (f. 75) 
Cosa clara es // Cést une chose claire \& manifeste (f. 77v)

es acariciado // est caressé \& chery (f. 78)

y a la diestra // a dextre \& a senestre (f. 89)

Es posible que algunas de las adiciones señaladas intenten afianzar el sentido del texto francés, con bimembraciones cuyos miembros son sinónimos o complementarios: el traductor pudo dudar de si habría aprehendido debidamente el sentido del término o el sintagma españoles, y haber optado por yuxtaponer una expresión equivalente. Pero el fin más común parece consistir en un encarecimiento del mensaje.

d) Omisiones. Como las adiciones, las supresiones son un fenómeno usual que se localiza en palabras o fragmentos breves del texto español. En muchos casos, el elemento elidido forma parte de una bimembración o plurimembración enfática:

en la diestra del padre y en el sacramento // en la dextre de son pere (p. 10v) o el divertimiento // om. (f. 13v)

misericordia y esperanza // misericorde (f. 20)

esta gente y este lenguaje y estos ministros // ceste sorte de gens et ces ministres (f. 24)

con privados ni con hermanos ni padre ni madre // avec les fauoris mais non pas mesme auec les freres ny la mere (f. 34v)

Y si no tiene ni conoce ni admite padre ni madre // s'il ny cognovit pere ny mere (f. 35)

su poder $y$ dignidad // sa puissance (f. 49v)

el proprio lado $y$ favor // la mesme faueur (f. 52v)

de los buenos y santos y leales // des bons \& loyaux (f. 57v)

y alimentado y crecido // et alimenté (f. 60)

ni Elías ni profeta // om. (f. 61)

sus peregrinaciones, sus trabajos, sus naufragios, sus afrentas, su miseria, sus martirios, sus azotes, su muerte // ses voyages, trauaux, naufrages, affront, flagellations, martiris, \& mort (f. 66)

el consejo y la advertencia // l'aduertissement (f. 77)

Otras veces refleja una circunstancia o información implícita y no estrictamente necesaria, de modo que la omisión tampoco produce cambios apreciables en el sentido:

o por el derecho de la sucesión legítima // ou droit de succession (f. 12v)

Dios como Dios // Dieu (f. 16) 
orar a Dios // prier (f. 31)

el rey verdadero Cristo // Jesus Christ (f. 35)

Respondieron: unos dicen que eres Juan Bautista; otros, Elías; otros, Jeremías; otros, que pareces uno de los profetas; otros, que resucitó uno de los profetas primeros // Les uns luy respondirent, ilz disent que tu es Jean Baptiste, les otres Helye, les autres Hieremie \& les autres un des prophetes (ff. 39v-40)

en la oración del huerto // dans le jardin (f. 45v)

obligación del buen rey cristiano hasta el corazón // L'obligation du bon rey (f. 46v)

Cristo nuestro señor // Jes. Ch. (f. 51v)

asi los llama el evangelista // om. (f. 52v)

sin acordarse de sí para los tabernáculos y mansiones // sans se souuenir de soy (f. 54)

compitiendo el cortejo al rey // om. (f. 64v)

San Juan Evangelista // Sainct Jean (f. 65)

en una de las siete palabras // om. (f. 65)

Que es buen pastor // om. (f. 72v)

y el primer memorial // Le premier (f. 81v)

el tercero y último // le troisiesme (f. 83)

como hijo de Dios, y como a Dios, pidiéndole milagros // come filz de Dieu (f. 84)

y quedan en peligro // om. (f. 86v)

El rey de Israel dijo a Josafat // Le roy d'Israel respondit (f. 87)

Considere con toda la alma // considere (f. 87v)

aquellas animosas palabras // ces paroles (f. 93)

En alguno de los ejemplos consignados, en concreto los segmentos «de los profetas [...] de los profetas» y «Dios [...] Dios», son posibles tanto una simplificación deliberada como un salto de igual a igual.

Ciertas omisiones más extensas, que nunca comprometen el sentido del discurso, pueden haberse derivado de la dificultad de trasladar al francés una expresión inusual o del afán de evitar expresiones consideradas redundantes:

dirán los que tienen devoción melindrosa que no le es posible al hombre imitar a Dios para respecto religioso, que es achaque malintencionado // Car quelques malicieux diront il n'est pas possible d'imiter Dieu (f. 15v)

Según el tiempo murió por los impíos, y según el tiempo murió por nosotros. Dos veces en cuatro renglones dice que murió según el tiempo Cristo Nuestro Señor // qu'il repete deux fois en quatre lignes Nostre Seigneur Jesus Christ est mort pour nous selon le temps (f. $18 \mathrm{v}$ ) 
Niñería es, pero suena al propósito // Ainsy (f. 28v)

le facilitare la inobediencia a tal ejemplo // om. (f. 51)

Repetir estas cosas más es celo que prolijidad // om. (f. 55)

y si es maña, ni disimula ni autoriza // om. (f. 57v)

y conociese que había mucho tiempo que estaba así // om. (f. 67v)

no quiero ahogar su estilo; en él se lee mejor todo // et dit ainsy (f. 72)

y cada uno presume de apoderarse de aquella voluntad, y nadie echa al otro sino por acomodarse // chacun presumera de se rendre puissant (f. 76)

con el nombre de la santa ciudad y con el templo // om. (f. 84)

No faltan, aunque son más infrecuentes, omisiones que parecen revelar un propósito de censura religiosa, por ejemplo cuando se eliminan los términos Talmud y Sanedrín o confesores; o también política, al evitarse la mención del italiano Bocalino y del español Maldonado, este último en dos ocasiones, o suprimirse el calificativo mal, referido al ministro, y la indignidad atribuida a un rey:

no faltan en el Talmud rabíes que le confiesan rey y pobre mendigo [...] Confiesan que será rey y pobre, y en el Sanedrín, al principio del capítulo Heloc // On ne manque pas de passages en Rabiez qui le declarent roy pauure, mendiant qui court les parties du monde, \& qu'il si trouvera a tonie demandant laumosne parmy li lipriux, di cetti sorti ilz aduancent sans erreur qu'il sera Roy \& pauure. Et au commencement du chapitre Heloc il est escrit (f. 11v)

conforme la difinición de Aristóteles, sólo es rey el que lo hace y, según Bocalino, nadie lo hizo de todos los reyes que ha habido // celuy qui l'essecute es roy, conformement a la définition d'Aristote di sorte que tous y ayant failly, par consequent aucun des roys du monde ne l'a esté» (f. $15 \mathrm{v}$ )

del mal ministro // du ministre (f. 72)

así lo declara Maldonado // om. (f. 82v)

y dice Maldonado // \& un autheur dit (f. 84)

Consejeros y allegados de los reyes, confesores y privados // Quelz doiuent estre les conseillers consisseurs \& fauoris des Roys (f. 86)

Ministros allegados y confesores // Les ministres \& conseillers (f. 86v)

por esa intención tan indigna de rey // Pour ceste cause (f. 88v)

Es posible que hubiese funcionado también alguna forma de censura en la omisión de la siguiente expresión, relativa a la elección por parte de Cristo de aquellos que le acompañaban: Escogió idiotas y pescadores // om. (f. 16)

Y algunos ejemplos parecen necesarias adaptaciones del texto sobre costumbres, espacios o instituciones españolas; se trataría de términos desconocidos, o al menos 
presumiblemente innecesarios desde la óptica de un lector francés, como las menciones de las Cortes, Castilla o el virreinato:

Podría en algunas concesiones de las Cortes y en los demás servicios // Seroit il possible qu'un prince dans les recompenses de service et dans la distribution des graces (f. 25v)

y en España y Castilla particularmente // et en Espagne particulierment (f. 58)

para el virreinato // om. (f. 82)

pues no se acuerda España de haber tenido rey en su persona y deseos, intención y virtudes más ajustado a la verdad y a la justicia, piedad y religión católica // puisque le rotaume n'a point memoire d'auoir en un roy, en sa personne, desirs, intentions \& vertus plus conforme a la verité justice pieté \& religion (f. 93)

e) Cambios de orden. La intrincada sintaxis quevediana en tantos pasajes de Política de Dios determina uno de los rasgos más destacados de la versión francesa: los cambios de orden de los constituyentes del período. El traductor reordena de modo sistemático los elementos del discurso para ganar claridad expositiva, evitar posibles ambigüedades y sortear eventuales dificultades interpretativas, derivadas de la acusada distancia entre el sujeto, el verbo y sus complementos, acentuada por la acumulación de incisos sucesivos de índole diversa. Pero el resultado no traiciona el sentido original.

Quien del patrimonio de vuestra majestad, de sus rentas y vasallos, de su regalo, de su casa, quita para diferentes desinios, sea para lo que fuere // Celuy qui pour des desseins differens retranche le domaine de vostri Majesté les plaisirs, la maison, ses rentes, celles de ses vassaux, soit pour quelque cause que se puisse estre (f. $24 \mathrm{v}$ )

con la pluma los dibuja San Juan, con la voz los nombra // S. ${ }^{t}$ Jean les dépeint avec la plume, les dénote avec la parole (f. 26v)

comulgádole, si bien hay opiniones en esto, y comido en un plato // l'eust communié, et eust mangé en un mesme plat (il y a diuerses opinions sur ce sujet) (f. 37)

Ante la ausencia de dificultad de un pasaje enumerativo simple, en otros casos se diría que el cambio de orden obedece al mero gusto del traductor o al propósito de establecer una gradación diferente de los términos implicados.

en favor de la necesidad para su confusión; bueno es que los apóstoles // en faveur de la necessité. Il est bon que les apostres pour leur confusion (f. 30)

a Pedro y a Jacobo y a Juan // Pierre, Jean \& Jacques (f. 45)

acción natural y forzosa y honesta // action honeste naturelle \& violente (f. 47) 
de Jacobo y Juan // di Jean \& Jacques (f. 49v), de Jean et de Jacques (f. 51v)

Juan y Jacobo // Jacques \& Jean (f. 52v)

gran criado y valido // son grand fauory \& seruiteur (f. 64v)

A quién han de ayudar y para quién nacieron los reyes. Ioan. Cap. V. // Pour qui sont naiz les roys \& a qui ilz douient ayder (f. 67v; al margen: «S. Jean chap. 5.») los mentirosos, la ambición y la maña // l'ambition, l'artifice \& les menteurs (f. $81 \mathrm{v}$ )

hallaréis vuestra perdición, quien os robe, quien os engañe // vous trouuerez qui vous volle \& vous tromppe, et en fin vostre perte (ff. 91-91v)

Como se observa, hasta cuatro veces se modifica la disposición de los personajes bíblicos Jacobo y Juan, presentados siempre en orden inverso en la traducción francesa.

Pero otros cambios, no estrictamente de orden, sino de disposición gráfica, provocan alteraciones significativas en un epígrafe. En el capítulo 16, la versión francesa cambia la posición de la primera frase del texto, «Al rey solas las obligaciones de su oficio y necesidades de su reino y vasallos le han de llevar tras sí», y la convierte en continuación del epígrafe «El rey ha de llevar tras sí los ministros, no los ministros al rey» en la traducción (f. 74v).

f) Otro tipo de cambios (sentido, entonación, técnica narrativa, introducción de citas...). Aunque su trascendencia es por lo general pequeña, a lo largo de la traducción abundan leves sustituciones, que afectan a alguna palabra aislada o expresión.

ni los rabies incrédulos // ny les Juifz (f. 12)

resucitando una alma y un cuerpo // ressuscitant un mort de quatre jours (f. 12)

rey y reino o de sus criados // roy, et esclave, ou de ses ministres (f. 12v)

sin que en él se quede alguna cosa // sans que le fauory s'en attribue aucune gloire (f. 23)

con las armas o con letras o con la hacienda y la persona // par les armes, affaires, negociations, \& personnes (f. 31v)

mortal // plus grande (f. 31v)

Simón Pedro [...] Simón Barjona // S.t Pierre [...] Simon filz di Jona (f. 40)

cuatro o seis renglones // cinq ou six lignes (f. 40)

la malicia de las pretensiones // la malice des demons (f. 50v)

y su valimiento tan conforme a la virtud y al parentesco // et leur courage \& firmité si conforme a la vertu \& parenté» (f. 52v)

dar audiencia los ministros es forzoso // Les audiences qui donnent les ministres sont violentes (f. 58) 
la ignorancia y la malicia del pueblo y de los príncipes // l'jgnorance du peuple $\&$ la malice des princes (f. $61 \mathrm{v}$ )

reino de su ministro // vassal di son ministre (f. 63)

consejos // conseillers (ff. 63v-64)

mas en el que tocare a desautorizar su casa y profanarla // Mais en celuy ou on touchera a son autorité \& a la profanation de sa maison (f. $71 \mathrm{v})$

para defensa de su nombre // pour la deffense de son Eglize (f. 79v)

les dijo que era camino, verdad y vida // il leur dist quil estoit le chemin de verité (f. $86 \mathrm{v}$ )

Señor, los vasallos de rey que tiene ministros y criados // Les vassaux, sire, les ministres \& seruiteurs du roy (f. $88 \mathrm{v}$ )

El cambio en el término forzoso por violentes, y en la redacción del período en que se inserta, supone una alteración de mayor calado: no es que los ministros estén obligados a dar audiencia, sino que todas las que dan son 'violentas'. Tal vez esté cambio se haya debido a la interferencia de un «falso amigo», relacionado con el adjetivo forcé, en la acepción de 'por la fuerza', cuando forzoso tiene el sentido de 'necesario' en este contexto. Otro tanto sucede un poco más adelante, cuando «es la forzosa pregunta de todas» se traduce, erróneamente, como «est la plus violente de toutes» (f. 68).

La modificación del enunciado puede ir acompañada también de una adición $\mathrm{u}$ omisión del traductor:

su lado y las sillas // les chaires aux costez de son thorne de gloire (f. 14v)

Tocó la pobre mujer la vestidura de Cristo // La paure femme qui toucha le bord de la robe de Jesus Christ, nous aprend que (f. 21v)

tres panes // cinq pains \& deux poissons (f. 32)

porque Satanás ha dicho que sus ministros todo lo quieren para sí // qui Satan et ses ministres veulent tout pour eux (f. 54)

Oiga vuestra majestad no a mí, pues no es mi pluma la que habla // Vostre Maiesté doit sçauoir n'est pas ma plume qui parle (f. 73v)

cerca de cuarenta varones // prez de quatre cens hommes prophetes (f. 87)

Los cambios en las citas bíblicas, particularmente la omisión de textos latinos, obligan en ciertos casos a añadir una introducción que evite una pérdida del sentido o una dificultad para el lector, o bien a modificar el comienzo o la redacción de un pasaje: 
La femme qui depuis douze ans estoit tourmentéé d'un flux de sang (f. 20v)

En sainct Luc. chap. 8. Jesus Christ nous enseigne la mesme chose par la bourrasque pendant la quelle il dormuit. L'Evangeliste dit qu'il (f. 28v)

Comme il se vit en ce que dist l'Evangeliste qui fut que comme (f. $41 \mathrm{v}$ )

lors quil se rencontre des personnes qui les luy veulent vendre; Ilz luy demandent (f. 61)

que sin introdución cortesana pidió el Centurión, Math. 8. Rogans eum, \& dicens: Rogando y diciendo. Dejo lo que dijo, pues mereció que dijese dél lo que nunca dijo de otro. Miratus est: Que se admiró. Ve // Car li Centurion sans estre jntroduit a la mode de la Court luy demanda en priant \& disant Seigneur Je ne suis pas digne \& Jes. Christ rendit ce tismoignage de luy qu'il n'auoit point veu de si grandi roy en Israël \& luy dit Va (f. 49v)

Entre los cambios que afectan a la técnica narrativa, son muy destacados aquellos que sustituyen la persona narrativa, especialmente cuando buscan sortear la apelación directa a un tú reconocido como el rey ${ }^{28}$, uno de los rasgos más polémicos y subversivos del tratado quevediano, por medio de una más indirecta e impersonal tercera persona. En tales casos, cabe aventurar la propia censura del traductor, quien habría querido evitar tan directa admonición a un monarca, hipotéticamente identificable como el rey de Francia en el nuevo espacio geográfico de difusión de la obra.

Entristéceste, porque conoces lo mal [...] di, rey, por qué dejas entrar en tu aposento [...] y por qué sientas a tu mesa y tienes a tu lado // Il est desplaissant par ce qu'il cognoist [...] Pourquoy laisse il entrer en sa chambre [...] et purquoy fait il assouir a sa table et tient il a son costé (ff. 43-43v)

Rey hipócrita, ¿quieres dar a entender [...] y disimulas [...] entristéceste tú [...] Ya que no miraste lo que ofrecias // Cést un roy hypocrite, celuy qui veut faire entendre [...] et il dissimule [...] Il s'a triste [...] \& puis qu'il ne considere pas ce qu'il offre (f. 43v)

y si sucediere, tome el azote, eche de $s u$ casa los que se la desautorizaren; no sólo los eche y los castigue, pero derríbeles las mesas y los asientos // Si cela arriue $q u$ 'elle prenne le fouet $\&$ chasse de sa maison ceux qui la luy descreditent. Non seulement elle les doit chasser \& punir, mais de plus leur renuerser \& tables \& sieges» (ff. 71-71v)

${ }^{28}$ Sobre los principales destinatarios de Política de Dios, reyes y consejeros, remito a C. Peraita (1997, pp. 67-69, quien recuerda que, según Quevedo, Cristo «bajó a impartir doctrina política a príncipes y ministros, no a todos los hombres» (p. 67). Más adelante, explica lo que denomina «la retórica deliberativa, enfocada a «la exhortación y, en su caso, la disuasión» (p. 98). 
En ciertas ocasiones lo que se pretende es desdibujar una primera persona narrativa, un yo identificable en alguna medida con el del autor Quevedo, sustituida por la tercera, que propicia un mayor distanciamiento del traductor respecto al escrito:

pretendo yo despachar // quil pretendit (f. $82 \mathrm{v}$ )

He advertido // Il faut prende garde (f. 84)

También es posible encontrar casos de modificación de la entonación original (la aserción puede convertirse en interrogación retórica, por ejemplo) o de la técnica y estilo del discurso:

cuando sean pastores los enviará // Mais quand ilz seront pasteurs que leur enuoira il? (f. 45v)

Culpa: piden las sillas. Acusación: No sabéis lo que os pedís. Pregunta y interrogatorio: ¿Podéis beber el caliz que yo he de beber? Respuesta: Podemos. Aceptaron sentencia: Beberéis mi cáliz, moriréis mi muerte // Demander les chaires c'est leur peché, Vous ne seauuiz ce que vous demandez, leur accusation, Pouviez vous boire le calice, leur esqueste $\&$ interrogatoire, Vous mourrez de ma mort [...] Voila leur sentence? (f. 53)

Una vez más, las transformaciones no parecen derivar de un propósito de cambiar de modo sustancial, o tergiversar, lo dicho por Quevedo: son la impronta de un traductor que parece resistirse a desaparecer del todo, velado enteramente por el texto original.

\section{Recapitulación}

La versión al francés manuscrita de Política de Dios parece haber derivado de alguno de los testimonios primitivos de la primera parte, y tal vez se realizó con el conocimiento o la mediación de Quevedo, a juzgar por la dedicatoria del anónimo traductor a Monsieur Maillot, posiblemente Gabriel Maillot, "contrôleur des guerres» y miembro de la corte de Luis XIII. De haber existido una relación directa entre Maillot y Quevedo, pendiente de documentar de forma fehaciente, sus implicaciones abarcarían presumiblemente más facetas que la ceñida al tratado político. Los textos preliminares evidencian también el éxito previo de la traducción francesa de uno de los Sueños, El alguacil endemoniado. Los datos que se deducen del códice, del siglo XVII, invitan a suponer que la labor traductora se hizo pronto, previamente a la muerte del autor.

A diferencia de lo sucedido con la primera versión francesa del Buscón, el traductor operó con respeto al diseño y propósito general del tratado: adiciones, 
omisiones, alteraciones del orden o cambios en la redacción no desdibujan la obra trazada por Quevedo. Aun permitiéndose ciertas licencias, y muy ocasionales censuras, legó al lector francés un texto fiel al original, que permitió conocer en su extensión, tal vez a una muy reducida élite cultural que tuvo acceso a la versión francesa, una de las más aclamadas obras quevedianas. Ahora poseemos datos concluyentes para afirmar que también llegó a Francia de inmediato, y en época presumiblemente temprana, esta pieza indispensable de la reflexión política de Quevedo, faceta que le acompañó toda su vida, salpicando textos de toda índole o conformando tratados completos como el que años más tarde dedicó a la historia de Marco Bruto.

El hallazgo de una traducción al francés desconocida de Política de Dios no cambia el hecho de que las obras de Quevedo más aplaudidas en Francia fueron burlescas: el Buscón y los Sueños concretamente. Pero obliga a matizar la idea, parcialmente errónea, de que otras vertientes de su escritura, como la política, fueron ignoradas o no interesaron en absoluto. Un único manuscrito no autoriza a deducir un éxito editorial. No obstante, su mera existencia y el aval que aporta para las afirmaciones de Duport con las que se abría este artículo, animan a inferir que el tratado quevediano, de acusada originalidad entre la literatura política de su tiempo, mereció la atención de pequeños círculos eruditos e intelectuales, fuera de España y en territorio francés. El azar de la transmisión textual y de la conservación de testimonios del pasado permite pensar que tal vez existieron otras fuentes manuscritas de la versión francesa de la obra y que incluso en algún momento pudo plantearse su llegada a la imprenta, o conoció alguna edición perdida, a partir de un original tan esmerado y completo como el que ahora se da a conocer. Bibliotecas públicas o particulares pueden albergar algún vestigio, hoy oculto, de una difusión que aún resulta oscura y difícil de trazar. Y hasta cabe la posibilidad de que la censura inquisitorial que recayó sobre las versiones primitivas de Política de Dios, a partir del Indice de Sotomayor ${ }^{29}$, en el que explícitamente se rechazaban todas las anteriores a la primera edición autorizada de Madrid, hubiese inhibido cualquier intento de difundir una versión francesa basada en el texto temprano castigado. Sea como fuere, el manuscrito localizado es una invitación a redoblar los esfuerzos para completar con nuevos testimonios la historia de la transmisión textual de la obra de Quevedo en territorio francés, ahora más reacia que nunca a un exclusivo encasillamiento en la materia jocosa.

${ }^{29}$ «Su Política de Dios, Gobierno de Cristo, impresa en Madrid, en virtud de privilegio del mismo autor, año de 1626, por la viuda de Alonso Martínez, se permite y no de otra impresión» (1640, p. 425), se lee en el Índice. Previamente, el de Zapata incluía, a propósito de Quevedo, «varias obras que se intitulan y dicen ser suyas, impresas antes del año de 1631 , hasta que por su verdadero autor reconocidas y corregidas se vuelvan a imprimir» (1632, f. 399). 


\section{Obras citadas}

ALONSO VELOSO, María José: «La recepción europea del Marco Bruto de Quevedo: traducciones hasta el siglo XVIII», La transmisión de Quevedo, coord. F. Gherardi y M. Á. Candelas Colodrón, Vigo, Academia Editorial del Hispanismo, 2015b, pp. 23-58.

ALONSO VELOSO, María José: «Los títulos de Quevedo», La Perinola, 19 (2015a), pp. 111-148.

ALONSO VELOSO, María José: «Noticia sobre una traducción al italiano de Doctrina moral de Quevedo», La Perinola, 17 (2013), pp. 203-228.

ALONSO VELOSO, María José: «Quevedo, antídoto contra los whigs y los tories en la Inglaterra del siglo XVIII», Signa, 25 (2016a), pp. 339-372.

ALONSO VELOSO, María José: «Un “instante antimaquiavélico” de Quevedo en Inglaterra: Christian Politicks contra tiranos ateos, discípulos de Satanás», Neophilologus (2016b), DOI 10.1007/s1 1061-016-9497-1.

ARBESÚ, David: «La manipulación ideológica de las obras de Quevedo en la Inglaterra del siglo XVII», La Perinola, 10 (2006), pp. 317-338.

ASTRANA MARÍN, Luis: Epistolario completo de don Francisco de Quevedo Villegas, Madrid, Instituto Editorial Reus, 1946.

BARKER, J. W.: «Notas sobre la influencia de Quevedo en la literatura inglesa», Boletín de la Biblioteca de Menéndez Pelayo, 21 (1945), pp. 429-435.

BARONE, Lavinia: La Carta a Luis XIII de Quevedo y la polémica antifrancesa en Italia en el siglo XVII, Pamplona, Eunsa, 2014.

CHENAYE-DESBOIS, M. de la: Dictionnaire de la noblesse, Paris, Antoine Boudet, 1775.

CROSBY, JAMES O.: The Sources of the Text of Quevedo's Politica de Dios, New York, Modern Language Association of America, 1959 (reimpresión en Millwood, New York, Kraus Reprint Co., 1975).

EHRLICHER, H.: «Quevedo en Alemania», La Perinola, 15 (2011), pp. 95-111.

EMINOWICZ, T.: «Sobre una traducción de la Política de Dios, de Francisco de Quevedo, al polaco», Dicenda, 3 (1984), pp. 273-277.

FERNÁNDEZ-GUERRA Y ORBE, A. (ed.): Francisco de Quevedo, Obras de don Francisco de Quevedo Villegas, BAE 23 y 48, Madrid, Atlas, 1946 y 1951, 2 volúmenes.

FRANCO-FURT, A. (pseud.): El tribunal de la justa venganza, ed. L. Astrana Marín, en Francisco de Quevedo, Obras completas. Obras en verso, pp. 1099-1163.

GARZELLI, Beatrice: «Traducción y mundos posibles. Los sueños de Quevedo traducidos al italiano», La Perinola, 15 (2011), pp. 157-169.

GENDREAU, Michelle: Héritage et création: Recherches sur l'humanisme de Quevedo, Lille, Champion-Université de Lille III, 1977.

JAURALDE, Pablo: Francisco de Quevedo (1580-1645), Madrid, Castalia, 1999. 
KWIATKOWSKA FARYS, Edyta: «Las traducciones polacas de Quevedo», Actas de la AISO, VI, 2002, pp. 1133-1140.

MARTINENGO, Alessandro y Diego SÍMINI: «La primera traducción italiana del Buscón», Estudios sobre el Buscón, coord. Alfonso Rey, Pamplona, Eunsa, 2003, pp. 273-294.

MÉRIMÉE, Ernest: Essai sur la vie et les oeuvres de Francisco de Quevedo (15801645), Paris, Alphonse Picard, 1866.

MOLL, Jaime: «Quevedo y la imprenta», De la imprenta al lector. Estudios sobre el libro español de los siglos XVI al XVIII, Madrid, Arcos, 1993, pp. 7-20.

MOROVELli DE PUEBLA, F.: Anotaciones a la Politica de Dios, gobierno de Cristo y tiranía de Satanás, Obras completas de don Francisco de Quevedo Villegas, ed. L. Astrana Marín, Madrid, Aguilar, pp. 985-993.

NAVARRO ERRASTI, María del Pilar: «Quevedo en lengua inglesa», De clásicos y traducciones: versiones inglesas de clásicos españoles (ss. XVI y XVII), Barcelona, PPU, 1987, pp. 165-187.

NIDER, Valentina (ed.): Una 'consolatio' de Quevedo: la Carta a Antonio de Mendoza, Firenze, Alinea Editrice, 2013.

NIDER, Valentina: «Nicolò Serpetro, traductor del Marco Bruto de Quevedo», La Perinola, 15 (2011), pp. 171-190.

NIDER, Valentina: «Texto y contexto de dos traducciones olvidadas: la Carta a Antonio de Mendoza de Quevedo y la Instrucción al Exercicio de la muerte de Luisa de Padilla, condesa de Aranda», Il prisma di Proteo: riscritture, ricodificazioni, traduzioni fra Italia e Spagna (sec. XVI-XVII), ed. V. Nider, Trento, Università degli Studi di Trento, 2012, pp. 481-504.

PACHECO DE NARVÁEZ, Luis: Memorial denunciando al tribunal de la Inquisición cuatro libros de D. Francisco de Quevedo, ed. Luis Astrana Marín, Francisco de Quevedo, Obras completas. Obras en verso, pp. 1043-50.

PERAITA, Carmen: Quevedo y el joven Felipe IV, Kassel, Edition Reichenberger, 1997.

QUEVEDO, Francisco de, Política de Dios: ed. E. Ma . Díaz Martínez (parte primera) y R. Cacho Casal (parte segunda), Obras completas en prosa, «Tratados políticos», dir. A. Rey, volumen V, Madrid, Castalia, 2012, pp. 159-639.

QUEVEDO, Francisco de: La fortuna con seso y la Hora de todos, ed. L. Schwartz, en Obras completas en prosa, dir. A. Rey, Madrid, Castalia, volumen I, tomo II, 2003, pp. 560-810.

QUEVEDO, Francisco de: Política de Dios, Govierno de Christo, edición de James O. Crosby, Madrid, Castalia, 1966.

QUEVEDO, Francisco de: Primera parte de la vida de Marco Bruto: ed. M. J. Alonso Veloso, en Obras completas en prosa de Quevedo, "Tratados políticos», dir. A. Rey, volumen V, Madrid, Castalia, 2012, pp. 647-990. 
QUEVEDO, Francisco de: Virtud militante contra las quatro pestes del mundo, invidia, ingratitud soberbia, avarizia, ed. A. Rey, Santiago de Compostela, Universidad, 1985.

REY, Alfonso: «Quevedo, Duport y la edición del Buscón», Journal of Hispanic Research, 3, (1994-1995), pp. 167-179.

REY, Alfonso: The Last Days of Humanism: A Reappraisal of Quevedo's Thought, Cambridge : Modern Humanities Research Association, 2015.

RICHELIEU, Armand Jean du Plessis (cardinal duc de): Mémoires du cardinal de Richelieu. T. VII [1627], dir. de M. Lacour-Gayet, par Robert Lavollée, Paris, Librairie Ancienne Honoré Champion, Société de l'histoire de France, 1926.

ROIG MIRANDA, Marie: «Edición y anotación de Les Visions del Sieur de La Geneste», La Perinola, 4 (2000), pp. 367-378.

ROIG MIRANDA, Marie: «La recepción de Quevedo en Francia», La Perinola, 15 (2011), pp. 235-261.

ROIG MIRANDA, Marie: «Las traducciones francesas de los Sueños de Quevedo en el siglo XVII y hasta 1812 (Nota bibliográfica)», en Quevedo a nueva luz: escritura y política, ed. L. Schwartz y A. Carreira, Málaga, Universidad, 1997, pp. 165-212.

SOTOMAYOR, A. de, Novissimus librorum prohibitorum et expurgadorum index, Madrid, 1640.

TARSIA, Pablo de: Vida de don Francisco de Quevedo y Villegas, ed. M. Prieto Santiago y F. B. Pedraza Jiménez, Aranjuez, Ara Iovis, 1988.

ZAPATA, Antonio, Novus index librorvm prohibitorvm et expurgatorum editus Auctoritate \& Iussu... D[omini] Antonii Zapata..., Hispali: Franciscus de Lyra, 1632. 